\title{
Successful and Unsuccessful Clinical Nursing Students
}

By: Lynne Porter Lewallen, Jacqueline Kayler DeBrew

Lewallen, LP, \& DeBrew, JK. (2012). Successful and unsuccessful clinical nursing students. Journal of Nursing Education, 51(7), 389-395. doi:10.3928/01484834-20120427-01

Made available courtesy of Slack, Inc.: http://www.dx.doi.org/10.3928/01484834-20120427$\underline{01}$
***@ Slack, Inc. Reprinted with permission. No further reproduction is authorized without written permission from Slack, Inc. This version of the document is not the version of record. Figures and/or pictures may be missing from this format of the document. ***

\begin{abstract}
:
This study describes the characteristics of successful and unsuccessful clinical performance in prelicensure nursing students. Clinical evaluation is an important role of nurse educators; however, many feel uncomfortable with its subjective nature, and commonly used criteria for successful and unsuccessful clinical performance are not available in the literature. Using a qualitative descriptive design, we analyzed telephone interviews with 24 nurse educators. Educators indicated successful students were positive and eager to learn, built relationships, communicated well, think critically, prepared for the clinical experience and showed progress, accepted feedback, and adapted to the clinical setting. Unsuccessful students were unprepared for the clinical experience, were unable to function in the clinical area, were unsafe, violated legal-ethical principles, and had difficulty with communication skills. Specific characteristics differentiated students who are considered satisfactory in the clinical area and those who are not. These behaviors may identify students at risk of failure in clinical courses.
\end{abstract}

Keywords: Nursing | Nursing Education | Clinical Experience

\section{Article:}

Evaluation of students in the clinical area is a critical role of nurse educators. Clinical experiences are the settings where students learn to "think like a nurse" (Benner, Sutphen, Leonard, \& Day, 2010 , p. 12), and they must include learning time, as well as evaluation time. Eventually, the educator must decide on a clinical grade. The National League for Nursing $\left({ }^{2005}\right)$ has noted that using assessment and evaluation strategies is a core competency for nurse educators. Most schools of nursing have clinical evaluation tools, usually based on course learning outcomes and student behaviors; nevertheless, clinical faculty have reported struggling at times to decide

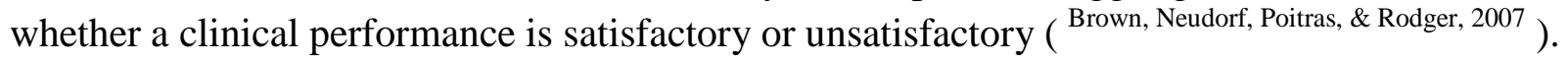

Most nurse educators would likely agree that failing a student is emotionally difficult and is especially stressful for novice and part-time faculty. Failed students sometimes report feeling 
singled out and penalized for the same mistakes other students also make but go unnoticed

( ${ }^{\text {McGregor, } 2007}$ ). Scanlan, Care, and Gessler $\left({ }^{2001}\right.$ ) found that some of the faculty's reluctance to fail students resulted from the belief that it was unfair to fail them early in the program because they needed time to learn and adjust to nursing school. Those authors also found that novice faculty were uncertain about clinical evaluation or believed that failing a student showed uncaring behavior toward the student. Because of student privacy issues, faculty members have reportedly been reluctant to discuss clinical evaluations with colleagues ( Diekelmann \& McGregor, 2003 ). The decision about whether to fail a student was therefore made in isolation, without opportunities to learn strategies from other faculty who may have faced similar situations. If faculty had better definitions of the characteristics that differentiate successful and unsuccessful students across clinical courses, such characteristics could serve as an early warning system to encourage early intervention with students at risk for clinical failure.

Clinical evaluation is critical for the learning of the student and also for patient safety. Clinical behaviors related to safety have been the topic of two recent studies. In a focus group study of nurse educators, Tanicala, Scheffer, and Roberts $\left({ }^{2011}\right)$ found that the context of the clinical situation, such as the level of the student and the timing in the semester, should affect the evaluation of clinical behavior, as should patterns of behavior, such as repetitive errors. As the first phase of a multiphase study, that research culminated in a clinical scenario-based survey to be tested in the future. Killiam, Montgomery, Luhanga, Adamic, and Carter ( ${ }^{2010}$ ) used Qmethodology with 57 students and 14 undergraduate clinical faculty in Canada to examine unsafe student practices. They asked their participants to respond to the statement, "In a clinical setting, practicing safely is at risk when an undergraduate student..." (p. 5). They found that unsafe students showed compromised professional accountability related to performing and documenting care; incomplete praxis, which was defined as taking on responsibility that the student was not ready for; and clinical disengagement, which was characterized by being unprepared for the clinical experience and not following the directions of the instructor. Although these studies provided insight into clinical evaluation, educators still have no comprehensive guide to evaluate students' performance. As a first step in this direction, our study was directed toward identifying behaviors that experienced nurse educators consider characteristic of successful and unsuccessful clinical performance in prelicensure nursing students.

\section{Method}

This study was part of a larger qualitative descriptive investigation ( ${ }^{\text {Sandelowski, 2000, } 2010}$ ) of the clinical evaluation process of prelicensure students. We interviewed 24 English-speaking nurse educators currently employed in prelicensure nursing programs in North Carolina. We randomly chose two schools from each of the following groups: the Mountains, Piedmont, and Coastal Plain geographical areas of the state, associate or diploma and baccalaureate programs, and publicly and privately financed institutions. We also included a sample of baccalaureate programs located in universities that are historically considered minority (established during the 
era of racial segregation to serve Black or American Indian students). The groups were chosen to be representative of different program types and geographical areas of the state, which resulted in 12 schools from which to sample. To be included, the educators had to have had at least the equivalent of 1 year of full-time clinical teaching experience with prelicensure RN students within the past 10 years. We sent e-mail invitations to participate in the study to all nursing faculty listed on the Web sites of the selected schools. The first two nurse educators from each school who responded and met study criteria were interviewed. Institutional review board approval was granted for the study, and each participant signed an informed consent form.

We conducted and audiotaped the interviews by telephone (although we offered the option for an in-person interview) at a time convenient to participants. The median length of the interviews was 54 minutes (range $=22$ to 83 minutes). Each author interviewed one educator per school. We e-mailed a list of open-ended questions to participants prior to the interview so they would have time to reflect on their responses.

We started each interview by asking the educators to describe students who were successful and not successful in the clinical setting. We then used probes (e.g., tell me more about that) to elicit clarification and further elaboration of responses, including those referring to topics that were not on the interview guide but which spontaneously arose during the interview. The authors discussed each interview after completion to ascertain whether any changes were needed. For example, one question was added regarding whether preceptors were used in the clinical courses taught by the participants. Because no new information was being heard after completing 24 interviews, we determined that saturation was reached.

The interviews were transcribed verbatim by a professional transcriptionist and then proofread by the interviewer who made any necessary corrections. We then proceeded with the analysis using the written transcripts. Both authors read each transcript several times. We separately summarized each interview (both those personally conducted and those conducted by the other researcher) and then examined these summaries for consistency. Inconsistencies were further addressed until we reached a negotiated consensus.

The data were analyzed using the data-derived form of qualitative content analysis described by Hsieh and Shannon $\left({ }^{2005}\right)$. No a priori codes were imposed; instead, codes were derived directly from the data. Initially, the responses to the interview questions were divided between the two authors for coding, but as analysis proceeded both authors examined each code together, frequently returning to the transcript for context until complete consensus was reached. We used

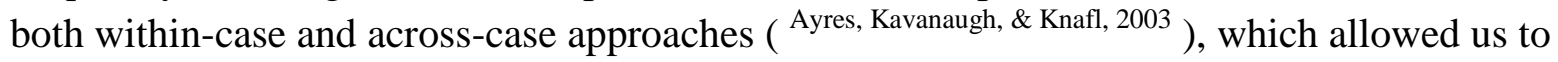
compare all the responses each participant gave to each question and to compare all the responses to each question. We looked for but did not find any evidence of recurring association among responses and participant demographics (e.g., type of nursing program, length of experience teaching, age, geographic area). 
The analysis of data led us to integrate all responses, addressing what nurse educators viewed as indicating satisfactory and successful student behaviors and unsatisfactory and unsuccessful student behaviors, with examples of each as shown in Tables $\mathbf{1}$ and $\mathbf{2}$. We were careful to code these behaviors separately and did not assume that an unsatisfactory behavior would simply be the opposite of a satisfactory behavior.

\section{Results}

The nurse educators who participated in the study were women, were predominantly (88\%) Caucasian, and had an average age of 47 years (range $=30$ to 59 years). Twenty-five percent of participants held a doctorate as the terminal degree, and the remainder held a master's degree in nursing. Participants had on average 11 years of experience in nursing education (range $=1$ to 30 years). Most (87\%) of the participants taught clinical groups in hospitals. Table $\mathbf{3}$ shows demographic details about the participants. None of the variation in these demographic characteristics was associated with the depiction of student characteristics as being successful or unsuccessful.

\section{Characteristics of Successful Students}

Table 1. Characteristics of Successful Students

\begin{tabular}{|c|c|}
\hline Characteristic (No. of Educators Represented) & Example of Behavior \\
\hline Is prepared for the clinical experience (19) & $\begin{array}{l}\text { Prepared, including bringing } \\
\text { needed resources to the clinical } \\
\text { experience }\end{array}$ \\
\hline \multicolumn{2}{|l|}{ Professional in dress and manner } \\
\hline \multicolumn{2}{|l|}{ Has researched medications and patient pathophysiology } \\
\hline \multicolumn{2}{|l|}{ Prompt with attendance and paperwork } \\
\hline \multicolumn{2}{|l|}{ Organized } \\
\hline $\begin{array}{l}\text { Able to think critically by integrating theory into the } \\
\text { clinical experience and develop plan of care for patients; } \\
\text { provides safe care (19) }\end{array}$ & $\begin{array}{l}\text { Strong knowledge base that is } \\
\text { applied in the clinical experience }\end{array}$ \\
\hline \multicolumn{2}{|l|}{ Safe practice } \\
\hline \multicolumn{2}{|l|}{ Able to use the nursing process } \\
\hline \multicolumn{2}{|l|}{ Pays attention to what is happening and makes connections } \\
\hline \multicolumn{2}{|l|}{ Critical thinker who is able to problem solve } \\
\hline \multicolumn{2}{|l|}{ Meets the objectives } \\
\hline \multicolumn{2}{|l|}{ Prioritizes } \\
\hline $\begin{array}{l}\text { Builds relationships and communicates with faculty, staff, } \\
\text { patients, and peers (17) }\end{array}$ & Effective communicator \\
\hline \multicolumn{2}{|l|}{$\begin{array}{l}\text { Shows respect to and works well with faculty, staff, peers, } \\
\text { and patients }\end{array}$} \\
\hline \multicolumn{2}{|l|}{ Asks appropriate questions } \\
\hline Has a positive attitude with eagerness to learn (16) & Seeks learning opportunities \\
\hline Eagerness to learn & \\
\hline
\end{tabular}




\begin{tabular}{|l|l|}
\hline Positive attitude & \\
\hline Self-motivated & \\
\hline Straightforward and self-assured personality & \\
\hline Caring & \\
\hline Open to learning & \\
\hline Engaged & Honest \\
\hline $\begin{array}{l}\text { Shows progress, accepts feedback, and adapts easily in the } \\
\text { clinical experience (11) }\end{array}$ & $\begin{array}{l}\text { Takes constructive feedback and } \\
\text { uses it to show progress and } \\
\text { growth }\end{array}$ \\
\hline Adaptable and flexible in the clinical setting & \\
\hline
\end{tabular}

Educators identified five characteristics of successful students in the clinical area. Successful students (a) were prepared for the clinical experience, (b) were able to think critically, (c) were able to build relationships and communicated well, (d) were positive and eager to learn, and (e) showed progress, accepted feedback, and adapted to the clinical setting.

Prepared for the Clinical Experience. The most common and often the first response from educators when asked to describe a successful student was "Successful students are prepared for clinical." One educator said, "They've thought ahead; what am I going to do today and what do I need to know in order to take care of that person?" Not only had successful students prepared their knowledge base but they had prepared themselves to look like a professional.

Able to Think Critically. Successful students were able to think critically, integrated theory into their clinical situation, developed a plan of care for their patients, and provided safe care. Successful students were able to demonstrate that their clinical preparation could translate into competent nursing care. One participant said, "[They] are able to independently plan, organize, and provide care to the patients assigned to them." Educators acknowledged that students still had a lot to learn, but successful students showed they were willing to use the knowledge they had gained so far. One educator commented, "I don't expect them to know everything there is to know...but I do expect them to have a good knowledge base and to build on that knowledge base." This critical use of knowledge enabled the student to provide safe care.

Able to Communicate. Successful students could build relationships and communicate (both verbal and written) with faculty, staff, patients, and peers. Not only were they ready to learn but they were not hesitant to speak up in the clinical experience. One participant said, "They can speak intelligently and professionally and knowledgeably about their patient and document the same." The students communicated with instructors openly with some give and take, rather than expecting the educator to provide all the answers. 
Positive Attitude. Successful students demonstrated a positive attitude and an eagerness to learn. Educators reported that this positive attitude was often present from the first day; "They're proactive, they know what they need to learn and they seek out those opportunities."

Adapt to the Clinical Setting. Successful students showed progress, accepted feedback, and adapted easily in the clinical setting. Clinical experiences are often unpredictable, and situations may arise for which the student has had no opportunity to prepare. Successful students could cope with this; "They're easily adaptable...this procedure is presented to us...[they] take that opportunity and run with it and learn what they can from it." Instructors reported providing frequent feedback to their clinical students, and successful students used that feedback to improve performance.

\section{Characteristics of Unsuccessful Students}

Table 2. Characteristics of Unsuccessful Students

\begin{tabular}{|l|l|}
\hline Characteristic (No. of Educators Represented) & Example of Behavior \\
\hline $\begin{array}{l}\text { Cannot function in the fast-paced clinical environment } \\
(23)\end{array}$ & Unmotivated, disinterested, scattered \\
\hline Unable to think critically & \\
\hline Too concrete & \\
\hline Lacks basic skills & \\
\hline Under the radar (i.e., tries to avoid being noticed) & Unsafe behaviors \\
\hline $\begin{array}{l}\text { Jeopardizes patient safety and commits legal--ethical } \\
\text { violations (22) }\end{array}$ & \\
\hline Legal--ethical issues & $\begin{array}{l}\text { Patterns of negative behaviors that } \\
\text { do not improve }\end{array}$ \\
\hline Overconfident & \\
\hline $\begin{array}{l}\text { Is not prepared for the clinical experience and does not } \\
\text { show improvement (20) }\end{array}$ & \\
\hline Unprepared for the clinical experience & \\
\hline Excessively tardy & \\
\hline Does not take responsibility for learning & \\
\hline Makes excuses & \\
\hline Not following school policies & \\
\hline Poorly written work & \\
\hline Immature & \\
\hline $\begin{array}{l}\text { Has difficulty in communication with patients, faculty, } \\
\text { peers, and clinical staff (12) }\end{array}$ & \\
\hline Poor professional communication & \\
\hline Received complaints & \\
\hline Does not show caring behaviors & \\
\hline
\end{tabular}


Table 3. Demographics of Educator Participants $(\mathrm{N}=24)$

\begin{tabular}{|c|c|}
\hline \multicolumn{2}{|c|}{ Demographics of Educator Participants $(N=24)$} \\
\hline Variable & Result \\
\hline Age & Mean $=47$ years, range $=30$ to 59 years \\
\hline Race & Caucasian = $21(88 \%) ;$ African-American = $1(4 \%) ;$ Asian = $2(8 \%)$ \\
\hline $\begin{array}{l}\text { Highest educational } \\
\text { level }\end{array}$ & $\begin{array}{l}\text { PhD = } 6 \text { (25\%; } 5 \text { nursing, } 1 \text { non-nursing); master's in nursing= } 18 \\
(75 \%)\end{array}$ \\
\hline $\begin{array}{l}\text { Type of nursing } \\
\text { program employment }\end{array}$ & Associate = $10(42 \%) ;$ baccalaureate $=14(58 \%)$ \\
\hline $\begin{array}{l}\text { Years of teaching } \\
\text { experience }\end{array}$ & Mean $=11$ years, range $=1$ to 30 years \\
\hline Usual clinical site & $\begin{array}{l}\text { Hospital = } 21(88 \%) \text {; long-term care = } 1(4 \%) \text {; outpatient = } 1(4 \%) \text {; } \\
\text { health department = } 1(4 \%)\end{array}$ \\
\hline $\begin{array}{l}\text { Usual patient } \\
\text { population in clinical } \\
\text { site }\end{array}$ & $\begin{array}{l}\text { Medical--surgical = } 15(62.5 \%) \text {; pediatrics = } 3(12.5 \%) \text {; mental health } \\
=2(8.3 \%) \text {; maternity = } 1(4.2 \%) ; \text { community health = } 1(4.2 \%) \text {; other } \\
=2(8.3 \%)\end{array}$ \\
\hline
\end{tabular}

Educators identified four characteristics of unsuccessful students in the clinical area. These students (a) were not able to function in the clinical area, (b) used unsafe practices and violated legal--ethical principles, (c) were not prepared for the clinical experience, and (d) were not able to communicate effectively.

Cannot Adapt to the Clinical Setting. Unsuccessful students could not function in the fast-paced clinical environment. Educators talked about the inability of unsuccessful students to apply previously learned material, use that knowledge in new situations, and organize their time to provide care in the clinical setting, which for our sample was typically a hospital. One educator said, "They can't think through something to the point of...how would I change this in this situation...they're just... kind of a passenger on the bus."

Safety and Legal--Ethical Issues. Unsuccessful students jeopardized patient safety and committed legal--ethical violations. Although these behaviors were not most frequently mentioned when educators talked about unsuccessful students, they were frequently identified as the most important. One instructor said, "Putting a patient at risk, or being unsafe, instantly qualifies [one] as a student who probably is not going to be successful." Although instructors sometimes had difficulty labeling a particular behavior as unsafe, violations of legal and ethical standards were clear indications of unsatisfactory performance.

Unprepared for the Clinical Experience. Unsuccessful students were not prepared for clinical experiences and did not show improvement. Faculty reported that unsuccessful students often started out unprepared: "They left their stethoscope at home or they didn't write all their meds. They come late, so they already come flustered." Despite frequent and detailed feedback, faculty often were not able to change this pattern of unsuccessful behavior. Frequently, these students 
did not take responsibility for their learning or unsatisfactory work. A lot of instructor time was spent in remediation efforts. One instructor said, "If they're not performing, I try to jump on that immediately and do something about it." Documentation of unsatisfactory behaviors was a critical part of the evaluation process. One participant noted, "The biggest thing, of course, is making sure that we have documentation; that the students receive due process."

Difficulty With Communication. Finally, unsuccessful students had difficulty communicating with patients, faculty, peers, and clinical staff. Educators thought that communication skills should improve as students went through the program. One said, "By the time they get to [the last course]...if they are unable to communicate effectively with either their clients or staff or physicians, or whomever...that...could be an issue for them."

\section{Characteristics That Differentiate Successful From Unsuccessful Students}

Looking at successful and unsuccessful students together, three categories describing these two types of students seemed to be opposites of each other: communication, preparation, and functioning in the clinical area.

Communication. Successful students could build relationships and communicate with faculty, staff, patients, and peers. Unsuccessful students had difficulty communicating with patients, faculty, peers, and clinical staff.

Preparation for the Clinical Experience and Use of Feedback. Successful students were prepared for the clinical experience. They showed progress, accepted feedback, and adapted easily in the clinical experience. Unsuccessful students were not prepared and did not show improvement.

Functioning in the Clinical Area. Successful students could think critically, integrating theory into clinical experiences, developing a plan of care for patients, and providing safe care. Unsuccessful students could not function in the fast-paced clinical environment.

Two categories did not present themselves as opposite ends of a continuum, but instead seemed to be unique to each type of student. These categories related to the student's attitude and patient safety concerns. Successful students had a positive attitude with an eagerness to learn. Unsuccessful students jeopardized patient safety and committed legal--ethical violations. Although elements of both of these categories were mentioned in the description of the opposites of each type of student (for example, successful students were described as safe, and unsuccessful students' attitudes were sometimes criticized), these were not mentioned frequently or independently enough to be considered separate categories.

\section{Discussion}

The literature shows that clinical evaluation is a critical role of nurse educators, and the educators in our study had carefully considered the characteristics of successful and unsuccessful students. Faculty described the successful student in greater detail than the unsuccessful student. 
A student could demonstrate readiness for and progress in the clinical area in many ways, but the study participants were more concise in describing behaviors that indicated a problem might be developing. This fact confirms the works of McGregor $\left({ }^{2007}\right)$ and Scanlan et al. $\left({ }^{2001}\right)$, who described the serious implications of clinical failure for both the faculty and the student; the responsibility of clinical grading was not taken lightly by these educators.

At times, educators may feel alone when making the decision to assign a failing clinical grade. Concerns about student privacy may prevent these educators from seeking support and guidance from their peers. However, it would not be a violation of confidentiality for faculty in the same course, all of whom have legitimate concerns about a student's progress in the course, discussed student issues together to offer support and guidance to each other. Sometimes, by discussing a situation with an experienced peer, new insights can be made into the behavior and new ideas about potential remediation can be found. Pseudonyms or discussion of specific behavior without using names could be used to protect student privacy.

A major characteristic of unsuccessful students was a pattern of poor work that did not improve. Often, the behaviors that warned faculty that a student might be heading for difficulty started early in the clinical rotation. Faculty reported that they spent a lot of time trying to remediate the student and struggled with the decision to assign a failing grade to him or her. As Tanicala et al. ( ${ }^{2011}$ ) reported, patterns of behavior are important to consider in clinical evaluation. Clearly, remediation opportunities must be offered, and if faculty can identify students' unsuccessful behavior early, remediation can start early. Perhaps the first day of the clinical experience would be a good time to talk with students about what kinds of things they should do to be successful. If a problem behavior can be managed early in the student's clinical experience, he or she is more likely to show progress and be successful later.

In our sample, clinical preparation was a key discriminator between successful and unsuccessful students, which is consistent with the findings of Killiam et al. $\left({ }^{2010}\right)$. Our educators reported that successful students were prepared, whereas unsuccessful students were not. Some students may not understand how to prepare for clinical experiences. Faculty should talk to students not just about the importance of being prepared for clinical experiences but also what that means. If expectations are indicated clearly at the beginning of the rotation, there is less room for misunderstanding, and remediation can be started early in the clinical rotation before no time is left for improvement. In addition, because successful students were consistently described as prepared, perhaps teaching students how to prepare well for clinical experiences may increase their chances of success.

Safety is critical and was identified by our participants as an important factor in determining whether a student would be successful. This is supported by influential organizations in health care, such as the Institute of Medicine $\left({ }^{2003}\right)$, and many curricular innovations now focus on

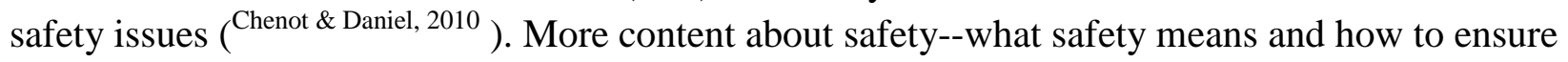
it--should be included in both didactic and clinical teaching. Clinical postconference time might 
be used to discuss specific examples of the areas of concern about safety on the particular unit; thus, students may then be more able to integrate what they learn in the classroom into the particular clinical setting.

Communication is critical in health care. The faculty in our study identified that the ability to communicate orally and in writing is a key discriminator between successful and unsuccessful students. Studies have shown that good communication with patients increases their compliance with treatment and decreases the risk of malpractice suits ( ${ }^{\text {Shipman, } 2010}$ ). As educators, we must remember that it is difficult for students to master the translation of the medical terminology they hear in the classroom and read in textbooks into the lay terminology in which they must teach and interact with patients. Classroom activities and clinical conference activities, such as roleplaying patient teaching sessions and therapeutic communication, can encourage students to better perform this skill. Also, communication is critical among health care professionals. For example, oral and written professional communication during hand-off reports is important to

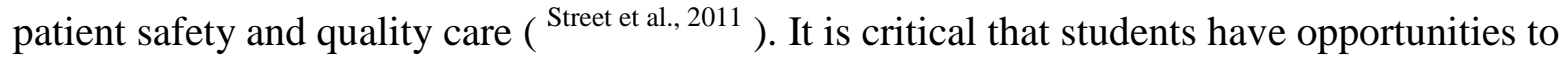
practice these types of interactions in the clinical setting. If every student does not get the opportunity, communication should be thoroughly discussed in clinical conferences, and roleplaying may be used to involve every student.

Most colleges and universities have writing and speaking centers, which assist students to develop these skills. Arranging for students to have the opportunity to practice professional writing and providing feedback and the opportunity to revise it can improve this skill. Practice in speaking, perhaps with short presentations in the postclinical conference, with feedback and the opportunity to revise, is also helpful.

Health care institutions are increasingly fast paced, and the educators in our study described the difficulty that unsuccessful students had working in this environment. Although this may be a maturational process as students progress through the program, they must be given increasing responsibility for multiple patients with the expectation that they will attend to the entirety of patient needs and supervise personnel to whom some care is delegated. This includes the monitoring of laboratory results, administration of medications, patient teaching, personal care, and communication with the patient's family, other staff, and physicians. In a clinical group of eight to 12 students, it is not possible for each student to be responsible for the total care of more than one patient each week; however, we should consider dividing students into teams, alternating multiple-patient assignments, using expert nurses as preceptors, and using simulated experiences. Our students must be prepared to function in the health care environments in which they will work after graduation. In addition, staff educators in institutions can work to create nurse orientation programs that help new nurses to gradually assume their full role in a supportive environment.

Many of the characteristics of successful students that our participants described may seem like common sense to nurse educators. We expect our students to come to the clinical experience 
prepared to care for their patients, dressed appropriately, with a positive attitude, and ready to communicate professionally with their patients, faculty, and staff on the unit. However, many of our beginning students may not know how to behave in a professional environment. Nothing in their personal lives or their previous workplaces may have prepared them to enter this hectic, intimate environment where professional formality is the norm, where initiating communication with strangers in vulnerable situations is vital, and where advanced preparation is the expectation. Therefore, student handbooks that indicate dress codes and clinical handouts with clinical preparation tools may not be enough to clarify clinical expectations. Clinical orientation should include in-depth discussions of the interpersonal skills and patterns that are expected on the patient unit, exactly what type of preparation is required and how to begin this preparation, and should include a discussion of the meaning of professional behavior. Because we, as nurse educators, are accustomed to the culture of the health care system, we sometimes forget that it is a foreign culture to many of our students.

\section{Limitations}

Due to the nature of qualitative research and its small sample size, generalization from this study cannot be made. In addition, although attempts were made to ensure the racial diversity of our sample, it was largely Caucasian; therefore, findings may not reflect the views of educators from other cultural backgrounds.

\section{Conclusion}

Although the participants in our study were nurse educators experienced in the clinical evaluation of students, many of the characteristics of successful and unsuccessful students they identified may not be found in clinical evaluation tools based on course learning outcomes. In this study, nurse educators reported that successful students often exhibited positive characteristics at the beginning of the clinical experience, but they were also able to use positive feedback to improve their skills and behaviors during the clinical rotation. Unsuccessful students often started the clinical experience unprepared and had difficulty using feedback to improve. Nursing faculty should clearly describe what is expected of clinical students, develop strategies to recognize unsuccessful behavior early in the rotation, and document unsatisfactory behaviors and progress toward improvement. Although clinical evaluation tools are prevalent, sometimes the behaviors and characteristics that contribute toward meeting clinical student learning outcomes are less defined. If both students and faculty are aware of what are considered unsatisfactory behaviors in the clinical area, the clinical evaluation of students will be less ambiguous.

\section{Footnote}

This study was funded by a National League for Nursing Research Grant. The authors thank Margarete Sandelowski her for assistance with qualitative analysis and Elizabeth Tornquist for editorial assistance. 
The authors have disclosed no potential conflicts of interest, financial or otherwise.

\section{References}

Ayres L , Kavanaugh K , Knafl K A , (2003). Within-case and across-case approaches to qualitative data analysis. Qualitative Health Research, 13, 871--883.

10.1177/1049732303013006008

Benner P , Sutphen M , Leonard V , Day L , (2010). Educating nurses: A call for radical transformation. San Francisco, CA: Jossey-Bass.

Brown Y , Neudorf K , Poitras C , Rodger K , (2007). Unsafe student clinical performance calls for a systematic approach. Canadian Nurse, 103(3), 29--32.

Chenot T M , Daniel L G , (2010). Frameworks for patient safety in the nursing curriculum. Journal of Nursing Education, 49, 559--568. 10.3928/01484834-20100730-02

Diekelmann N , McGregor A , (2003). Students who fail clinical courses: Keeping open a future of new possibilities. Journal of Nursing Education, 42, 433--436.

Hsieh H-F , Shannon S E , (2005). Three approaches to qualitative content analysis. Qualitative Health Research, 15, 1277--1288. 10.1177/1049732305276687

Institute of Medicine. (2003). Patient safety: Achieving a new standard for care. Retrieved from http://iom.edu/Reports/2003/Patient-Safety-Achieving-a-New-Standard-for-Care.aspx

Killiam L A, Montgomery P , Luhanga F L , Adamic P , Carter L M , (2010). Views on unsafe nursing students in clinical learning. International Journal of Nursing Education Scholarship, 7, Article 36. doi:

McGregor A , (2007). Academic success, clinical failure: Struggling practices of a failing student. Journal of Nursing Education, 46, 504--511.

National League for Nursing. (2005). The scope of practice for academic nurse educators. New York, NY: Author.

Sandelowski M , (2000). Whatever happened to qualitative description? Research in Nursing \& Health, 23, 334--340. 10.1002/1098-240X(200008)23:4<334::AID-NUR9>3.0.CO;2-G

Sandelowski M , (2010). What's in a name? Qualitative description revisited. Research in Nursing \& Health, 33, 77--84.

Scanlan J M , Care W D , Gessler S , (2001). Dealing with the unsafe student in clinical practice. Nurse Educator, 26, 23--27. 10.1097/00006223-200101000-00013 
Shipman B , (2010). The role of communication in the patient--physician relationship. Journal of Legal Medicine, 31, 433--442. 10.1080/01947648.2010.535427

Street M , Eustace P , Livingston P M , Craike M J , Kent B , Patterson D , (2011).

Communication at the bedside to enhance patient care: A survey of nurses' experience and perspective of handover. International Journal of Nursing Practice, 17, 133--140. 10.1111/j.1440172X.2011.01918.x

Tanicala M L , Scheffer B K , Roberts M S , (2011). Defining pass/fail nursing student clinical behaviors phase 1: Moving toward a culture of safety. Nursing Education Perspectives, 32, 155-161. 10.5480/1536-5026-32.3.155

\section{AuthorAffiliation}

Dr. Lewallen is Associate Professor, and Dr. DeBrew is Clinical Professor, The University of North Carolina at Greensboro, School of Nursing, Greensboro, North Carolina.

Address correspondence to Lynne Porter Lewallen, PhD, RN, CNE, ANEF, Associate Professor, The University of North Carolina at Greensboro, School of Nursing, PO Box 26170, Greensboro, NC 27402-6170; e-mail: lplewall@uncg.edu. 